\title{
The Diagnostic Stability in Dual Diagnosis Study on a Sample of Patients with Opiate Addiction
}

\author{
Pasqualina Rocco, Roberto Manera and Graziano Bellio \\ Dependence Department, Local Health Unit n.8 Veneto, Italy
}

\begin{abstract}
It is known that in psychiatry, despite the introduction of standardized system, there is still a portion of diagnostic instability. This study aims to evaluate the stability of psychiatric diagnoses in a cohort of patients with dual diagnosis, under treatment of the Dependence Department of the Local Health Unit n.8 Veneto, Italy. 34 patients with opioid dependence, in treatment with methadone or buprenorphine, have been evaluated. They had participated to a previous study in 2006, in which psychiatric comorbidity was documented. These 34 patients have been retested with some of the tests already used in 2006: M.I.N.I. (for Axis I) and S.C.I.D. II (for Axis II). The preceding evaluations and those current have been compared to assess the stability of psychiatric diagnosis. Almost all patients (95\%) had at least a change of diagnosis. Psychoses are the most stable diagnoses. Also the substance use disorder is quite stable (80\%). Neuroses are more unstable. Personality disorders showed greater variability. Personality disorders appear more unstable in dual diagnosis. The diagnosis of personality disorder based on DSM, common in drug addicts, requires caution. Anyway, the longitudinal observation is important for a correct diagnosis.
\end{abstract}

Key words: Diagnostic stability, dual diagnosis, psychiatric comorbidity.

\section{Introduction}

The problem of diagnosis is very important for prognosis, therapy and research.

A reliable diagnosis is also needed in terms of service planning [1].

In psychiatry, important causes of diagnostic unreliability are attributed to the psychiatric nomenclature [2].

The introduction of structured classifications and standardized tests has made diagnosis much more homogeneous and stable than in the past.

However, the diagnostic variability still remains relatively high [3].

A major criterion for validating diagnoses is stability over time.

Diagnostic stability is the agreement between two consecutive diagnoses in the same patient [4]. There must be a gap of at least a year between the two observations [3]. If it is less, it is likely that the

Corresponding author: Pasqualina Rocco, Dr. Med., research field: Vitamin D and VDR-gene. difference between diagnoses depends on variance and not on diagnostic instability [5].

Diagnostic stability is closely correlated to reliability, which is the level to which 2 separate healthcare workers agree on a diagnosis [6].

It is important to assess diagnostic stability, especially for the following reasons [3]: to define homogeneous diagnostic groups, for diagnostic reliability, for research on the development of psychiatric disorders, for a full definition of medical opinion, and for the validity of the diagnostic construct.

In psychiatry, diagnostic categories have different stabilities.

Major psychotic disorders are stable, followed by drug addiction, then obsessive-compulsive disorders. Neurotic conditions are less stable. Personality disorders are more unstable [3, 7].

Comorbidity further reduces diagnostic stability [8].

Comorbidity is common in patients who are drug addicts, therefore diagnostic stability is lower, meaning the risk of a wrong diagnosis is higher. 
For example, psychotic disorders, which are known to be more stable, require special attention if there is substance abuse, because the diagnosis could change over time [9].

Personality disorders become even more unstable if they exist alongside drug addiction [5].

While several studies have investigated the diagnostic stability of single disorders, less is known about psychiatric comorbidity and dual diagnosis.

These considerations aroused our interest and we decided to assess diagnostic stability in our own work context.

\section{Methods}

\subsection{Design of the study}

Between 2003 and 2006 our department carried out research into the prevalence of dual diagnosis in outpatients with opiate addiction [10]. In 200690 outpatients had completed the study: among these, 48 had a dual diagnosis.

In 2013 we called these 48 patients back. They couldn't all be registered: 2 deceased, 9 transferred or discharged, 1 refusal.

In the end 36 patients were registered.

\subsection{Sample}

In 2003 patients with opiate addictions who had been receiving treatment with methadone and buprenorphine for at least 6 months were recruited. This group was chosen on the basis of stability characteristics.

The sample (2014) consisted of 34 outpatients. Sample mean age was 40.4. The majority were male (88.2\%), single (82.3\%), with an educational level of 8 years $(70.5 \%)$ and employed (55.8\%).

For socio-demographic characteristic details see Table 1.

\subsection{Instruments}

Standardized tests were used for the research: M.I.N.I. (Mini International Neuropsychiatric
Interview) [11] for Axis I and S.C.I.D. II (Structured Clinical Interview for DSM IV) [12] for Axis II.

After 10 years we decided to use the same tests on the same group of patients with dual diagnosis.

36 patients repeated the M.I.N.I and S.C.I.D. II tests and by the end 34 patients had completed the standard assessment.

The current study scheme is in Fig. 1.

\section{Results}

Only 2 patients had the same diagnosis: one with bipolar disorder, panic disorder, unspecified personality disorder and addiction (opiates, cannabinoids, cocaine); the other patient was suffering from an unspecified psychotic disorder and opiate addiction. All the other patients (roughly 95\%) presented with a diagnosis change: appearance of one or more new diagnoses, remission of one or more diagnoses, or one or more shifts between diagnoses.

Check the results of the M.I.N.I. test (Axis I) (Fig. 2).

Bipolar disorder is stable, even psychotic disorders are quite stable.

Major depressive episodes (in progress) decreased by $50 \%$.

With regard to anxiety disorders, agoraphobia, social phobia, obsessive-compulsive disorder and general anxiety disorder have shown some instability.

Panic disorder is stable.

Substance use disorder is also stable. In 2006 all 34 patients were being treated for opiate addiction. In 201410 patients (29\%) were no longer receiving agonist therapy because opiate addiction was being in remission, but only 2 of them were discharged. Apart from 3 patients who are still receiving care for psychiatric disorders and 1 patient for gambling addiction, 4 are still presenting with substance abuse (3 taking cannabinoids and 1 cocaine). In total substance abuse is stable in roughly $80 \%$ of cases (Fig. 3).

We can observe what happened with Axis II (Fig. 4). 
Table 1 Socio-demographic characteristics.

\begin{tabular}{|c|c|c|c|c|c|}
\hline & & 2006 & & 2014 & \\
\hline & N. patients & 48 & & 34 & \\
\hline & Mean age & 33.33 & & 40.4 & \\
\hline \multirow{2}{*}{ Gender } & Male & 43 & $89.5 \%$ & 30 & $88 \%$ \\
\hline & Female & 5 & $10.5 \%$ & 4 & $11.7 \%$ \\
\hline \multirow{5}{*}{ Educational level } & Elementary (5 years) & 3 & $6.3 \%$ & 1 & $2.9 \%$ \\
\hline & (8 years) & 30 & $62.5 \%$ & 24 & $70.5 \%$ \\
\hline & Vocational school & 5 & $18.8 \%$ & 3 & $88 \%$ \\
\hline & Middle school (12-13 years) & 9 & $10.4 \%$ & 5 & $14.7 \%$ \\
\hline & Graduate & 1 & $2.1 \%$ & 1 & $2.9 \%$ \\
\hline \multirow{3}{*}{ Marital status } & Single & 34 & $70.8 \%$ & 28 & $82.3 \%$ \\
\hline & $\begin{array}{l}\text { Married/ } \\
\text { cohabiting }\end{array}$ & 12 & $25 \%$ & 3 & $8.8 \%$ \\
\hline & $\begin{array}{l}\text { Separated/ } \\
\text { Divorced }\end{array}$ & 2 & $4.2 \%$ & 3 & $8.8 \%$ \\
\hline \multirow{4}{*}{ Employed } & Employed & 27 & $56.3 \%$ & 19 & $55.8 \%$ \\
\hline & Occasionally employed & 7 & $14.3 \%$ & 4 & $11.7 \%$ \\
\hline & Unemployed & 11 & $22.9 \%$ & 4 & $11.7 \%$ \\
\hline & Retired/ disabled & 3 & $6 \%$ & 7 & $20.5 \%$ \\
\hline
\end{tabular}

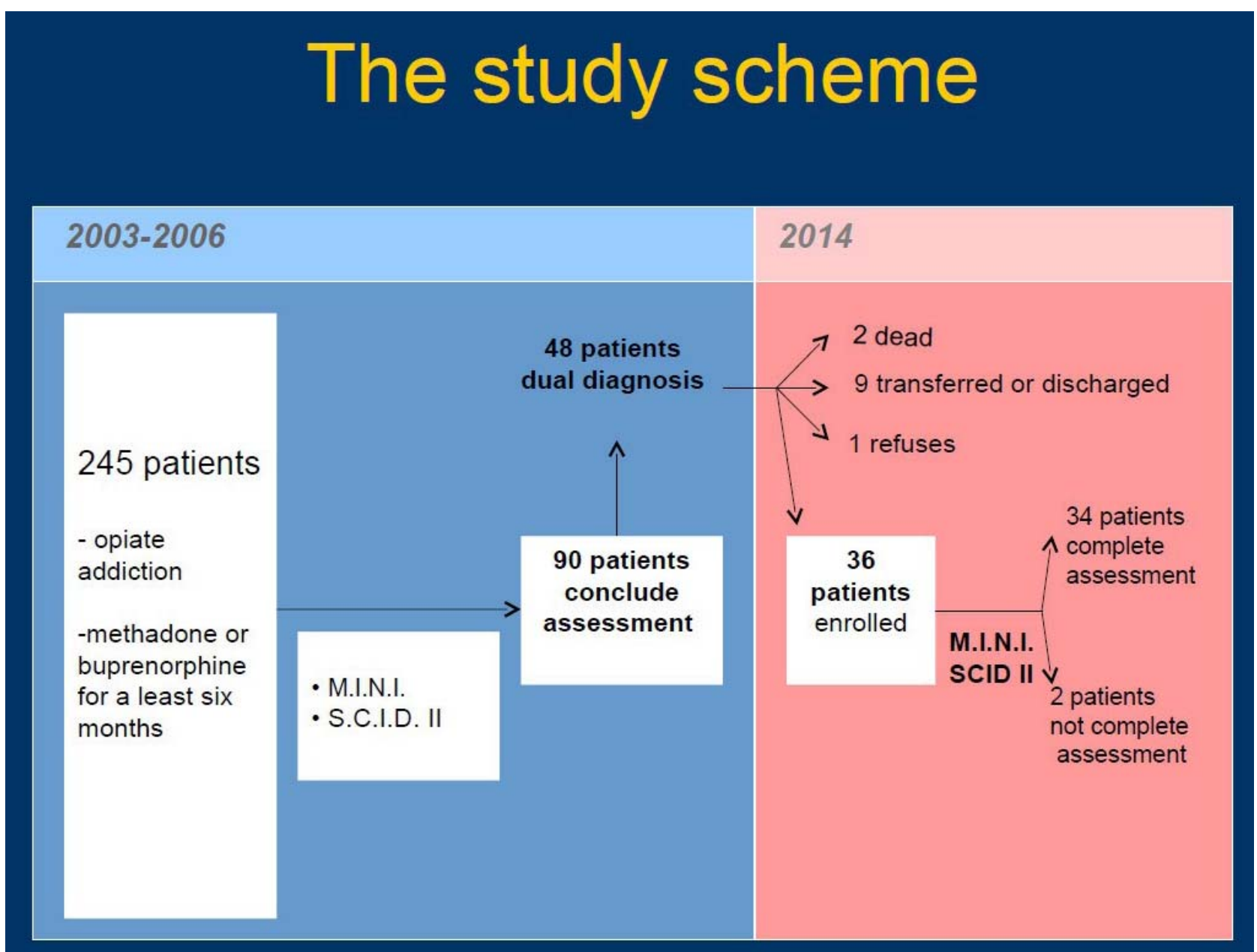

Fig. 1 The study scheme. 


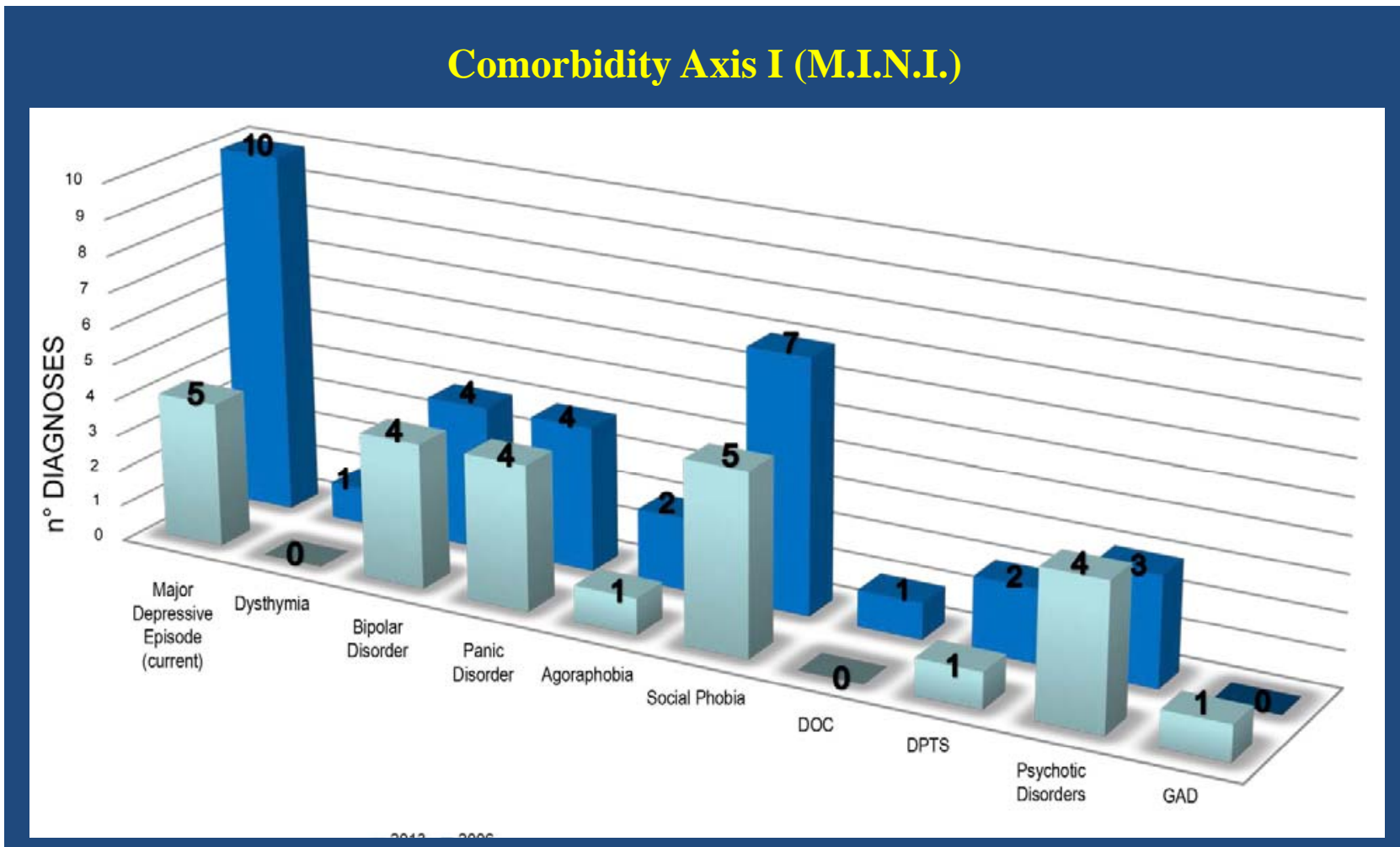

Fig. 2 Comorbidity Axis I (results test M.I.N.I).

\section{AXIS I: drug addiction}

\section{6 - 34 Patients}

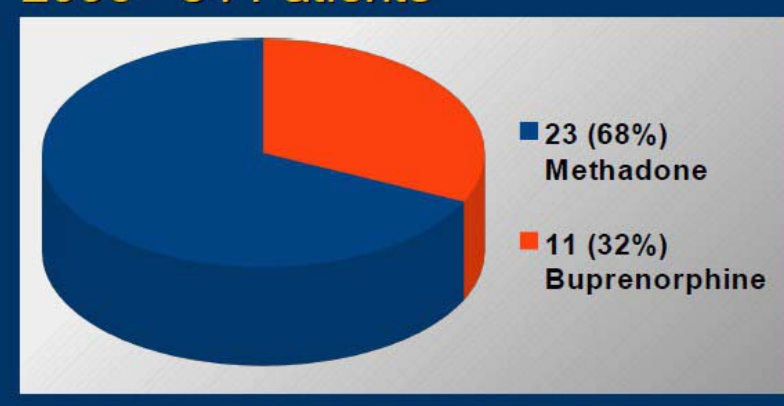

Fig. 3 Drug addiction.
2014 - 34 Patients
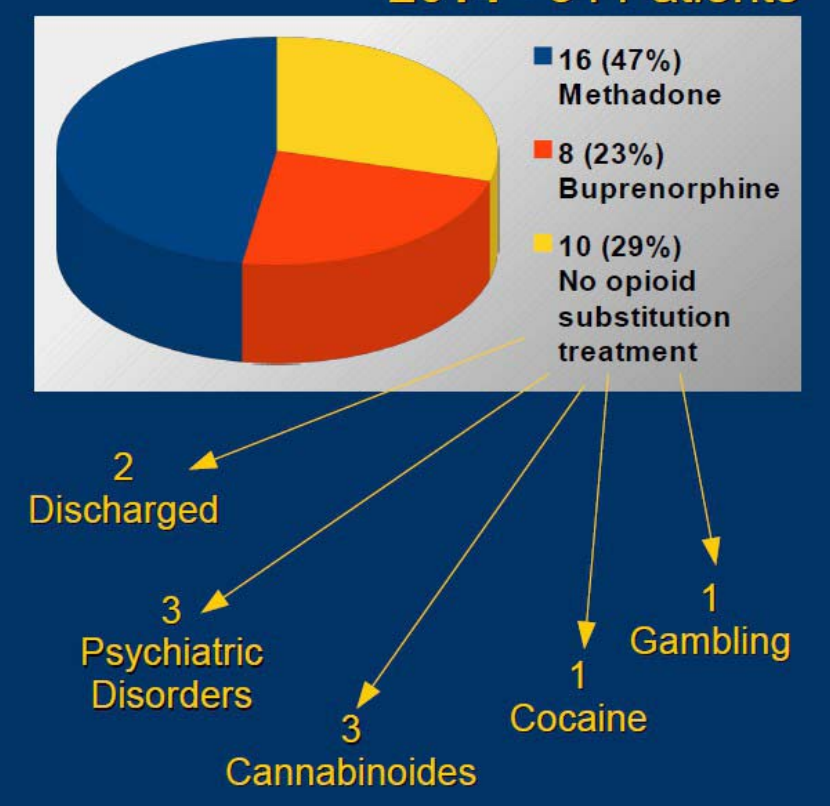


\section{Diagnostic variations Axis II}

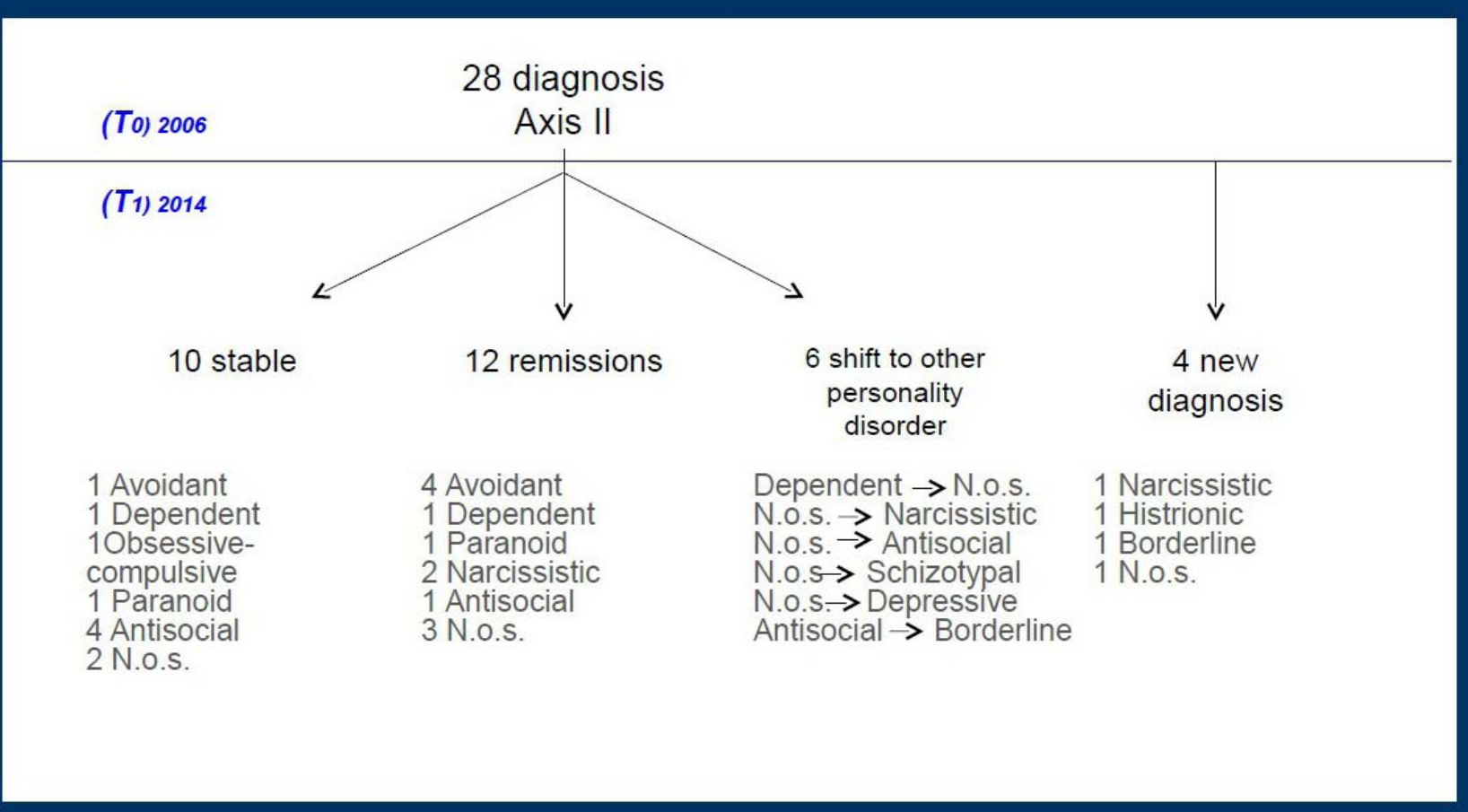

Fig. 4 Diagnostic variations Axis II (results S.C.I.D. II).

Only 10 diagnoses remained stable (about 35\%), 12 went into remission, 4 new diagnoses appeared and 6 shifted to another personality disorder. Among those that shifted, 4 unspecified personality disorders were categorized as narcissistic, antisocial, schizotypal and depressive.

A personality dependent disorder turned into an unspecified personality disorder and an antisocial case turned into a borderline case.

The 4 new diagnoses of personality disorder which were not there previously are: histrionic, borderline, narcissistic and unspecified.

Overall—personality disorders show considerable instability.

\section{Discussion}

This study presents several opportunities to discuss.

The major psychoses: bipolar disorder and schizophrenia are stable. The results are consistent with the literature [3, 7].
The M.I.N.I. is able to discriminate the major depressive episode "in progress" or "lifetime". With respect to the lifetime episode, the memory of that is preserved for all patients. But only $50 \%$ of patients still had an episode in 2014.

The reduction of major depressive episodes (in progress) is compatible with the episodic nature of the condition and the ongoing treatment.

Also the instability of neurotic disorders is compatible whit their episodic nature.

Only panic disorder is stable. Although the number of patients is too low, this aspect is interesting. Some authors think that panic disorder is "a stable clinical entity" and not a "general neurotic syndrome" [13].

Drug addiction is stable (about $80 \%$ ), in accordance with its definition and with the literature [14].

We see now the Axis II.

Out of all the personality disorders the antisocial condition seemed a bit more stable than the others. This is reported in the literature [15] and can be due to 
several causes. First and foremost, the S.C.I.D. II for this disorder is based on more objective criteria. Secondly, this personality disorder has been historically studied more, and therefore is more defined in its characteristics.

Other personality disorders are very unstable.

We think that the DSM classification of personality disorders is problematic.

Indeed, the long period of diagnostic stability resulted very important in order to define the diagnostic consistency.

The considerable instability of personality disorders call the DSM definition into question.

The DSM actually defined personality disorders as stable and enduring [4, 16]. The concept that personality disorders are enduring stems from the theory. In reality there is little empirical evidence to support this definition [17].

The classification of personality disorders was already considered as unsatisfactory in the DSM IV, mainly for the following reasons [18]: ill-defined mental illness/health boundaries, high comorbidity anomaly between personality disorders, uncertain stability for many personality disorders, little focus on the experience and subjective variables of the individual patient, low availability of personality disorders in clinical practice, uncertain boundaries between personality disorders and disorders in Axis I.

As a result, a significant review of DSM V was expected, which did not transpire however [19].

Contrary to the original plans, DSM V did not made radical changes in personality disorders.

This problem has significant implications for prognosis and treatment.

Some authors justify low investment in resources for these disorders on the basis of their unchanging nature. However, more recent literature has indicated the possibility of treating personality disorders and sometimes changing this trend [20,21].

Furthermore, this concerns a significant number of patients and especially drug addicts, who present with a high percentage of comorbidity and personality disorders [22].

An Italian study reported that $62 \%$ of patients who access a public facility for addiction have a personality disorder [23].

Axis II comorbidity has substantial effects on social and occupational functioning as well as on treatment programs.

Therefore we think it's advisable to exercise caution when formulating a diagnosis, and longitudinal observation is required.

The critical points of our study may be few in number sample and moreover not all diagnoses are represented.

On the other hand, its strengths are: the standardized evaluation and the wide time interval considered.

\section{Conclusions}

The results of this study are consistent with the literature: the major psychoses are stable and even drug addiction. Neurotic disorders are less stable, except panic disorder, which is stable. Personality disorders are very unstable.

The instability of personality disorders can be a problem, because this diagnosis is common in drug addicts.

The diagnosis of personality disorder based on DSM, especially in dual diagnosis, requires caution.

Anyway, the longitudinal observation is important for a correct diagnosis.

Based on our experience we hope that future studies will contribute to improve the diagnosis of these disorders, and therefore treatment of our patients.

\section{References}

[1] Atwoli, L., Ndambuki, D., Owiti, P., Manguro, G., and Omulimi, N. 2012. "Short-term diagnostic stability among re-admitted psychiatric in-patient in Eldoret, Kenya.” Afr. J. Psych. 15 (2): 114-8.

[2] Aboraya, A., Rankin, E., France, C., El-Missiry, A., and Collin, J. 2006. "The reliability of psychiatric diagnosis revisited.” Psychiatry (Edgmont) 3 (1): 41-50. 
[3] De Vanna, M., Peressutti, P., and Aguglia, E. 2001. "La stabilità diagnostica in psichiatria (diagnostic stability in psychiatry).” Rivista di Psichiatria 36 (5): 276-85. (in Italian)

[4] American Psychiatric Association 2013. Diagnostic and Statistical Manual of Mental Disorders (5th ed.) (DSM-V), Washinton, D.C., APA.

[5] Ferro, T., Klein, D. N., Schwartz, J. E., Kasch, K. L., and Leader, J. B. 1998. "30-month stability of personality disorder diagnoses in depressed out patient.” Am. J. Psych. 155 (5): 653-9.

[6] Migone, P. 1995. Alcuni problemi della diagnosi in psichiatria (some problems of diagnosis in psychiatry). Il ruolo terapeutico 70: 28-31. (in Italian)

[7] Baca-Garcia, E., Perez-Rodriguez, M. M., Basurte-Villamor, I., Fernandez del Moral, A. L., et al. 2007. "Diagnostic stability of psychiatric disorders in clinical practice.” Br. J. Psychiatry 190: 210-6. 10.1192/bjp. bp. 106.024026.

[8] Pope, M., Joober, R., and Malla, A. K. 2013. “Diagnostic stability of first-episode psychotic disorders and persistence of comorbidity psychiatric disorders over 1 year.” Can. J. Psychiatry 58 (10): 588-94.

[9] Sara, G. E., Burgess, P. M., Malhi, G. S., et al. 2014. "The impact of cannabis and stimulant disorders on diagnostic stability in psychosis.” J. Clin. Psychiatry 75 (4): 349-56.

[10] Manera, R., Gallini, P., Bellio, G., and Fioritti, A. 2007. "Prevalenza della comorbilità psichiatrica in pazienti con dipendenza da oppiacei in un SerT del Veneto. (prevalence of psychiatry comorbidity in patients with opioid dependence in an italian drug addiction service) Psichiatria di comunità.” Centro Scientifico Editore 6 (3) 181-5. (in Italian)

[11] Lecrubier, Y., Sheehan, D., Weiller, E., Amorim, P. et al. 1997. "The Mini International Neuropsychiatric Interview (M.I.N.I.). A short diagnostic structured interview: reliability and validity according to the CIDI.” Europ. Psych. 12: 224-31. Italian version of Conti L., Rossi A., Donda P. Mini International Neuropsychiatric Interview. Università degli studi di Pisa, Italia.

[12] First, M. B., Gibbon, M., Spitzer, R. L., Williams, J. B. W., and Benjamin, L. S. 2010. SCID-II Structured
Clinical Interview for DSM-IV Axis II disorders. Italian version of Mazzi F., Morosini P., De Girolamo G., Guaraldi G.P. Organizzazioni Speciali, Firenze.

[13] O’Rourke, D., Fahy, T. J., and Prescott, P. 1996. “The Galway Study of Panic Disorder IV. Temporal stability of diagnosis by present state examination test-retest.” $\mathrm{Br}$. $J$. Psychiatry 169 (1): 98-100.

[14] Vollemberg, W. A. M., Iedema, J., Bijl, R. V., De Graaf, R., Smit, F., and Ormel, J. 2001. "The structure and stability of common mental disorders: the NEMESIS study.” Arch. Gen. Psychiatry 58 (6): 597-603.

[15] Dinwiddle, S. H., and Daw, E. W. 1988. "Temporal stability of antisocial personality disorder: blind follow-up study at 8 years.” Comprehensive Psychiatry, 1998, 39: 28-34.

[16] American Psychiatric Association 2000. Diagnostic and Statistical Manual of Mental Disorders (4th ed., text revision) (DSM-IV-TR), Washinton, D.C., APA.

[17] Nestadt, G., Di, C., Samuels, J. F., et al. 2010. “The stability of DSM personality disorders over twelve to eighteen years.” J. Psychiatr. Res. 44 (1): 1-7.

[18] URL: Riflessioni sul DSM-5. (reflection on the DSM V) Mario Rossi Monti e Chiara Tarantino [http://www.osservatoriopsicologia.com/2013/09/21/rifles sioni-sul-DSM-5-mario-rossi-monti-e-chiara-tarantino/], consulted on 24/9/14. (in Italian)

[19] Moller, H. J. 2014. "The consequences of the DSM-5 for psychiatric diagnosis and psychopharmaco therapy." Int. J. Psychiatry Clin. Pract. 18: 78-85.

[20] Saccon, D., Banon, D., and Boatto, E. 2013. Evoluzioni nelle dipendenze da sostanze (change in substance addiction). Ed. Cleup, 25-85. (in italian)

[21] Vergara-Moragues, E., Gonzales-Saiz, F., Lozano, O. M., and Verdejo Garcia, A. 2013. "Psychopathological stability of personality disorders in substance abuse treated in a therapeutic community." $J$. of Addictive Diseases 32 (4): 343-53.

[22] Gonzalez, C. 2014. "Screening for personality disorder in drug and alcohol dependence.” Psychiatry Res. 217 (1-2): 121-3.

[23] Casadio, P., Olivoni, D., Ferrari, B., et al. 2014. "Personality disorders in addiction outpatients: prevalence and effect on psychosocial functioning." Subst. Abuse 8: 17-24. 